\title{
LAS ALUSIONES A LA LITERATURA ESPAÑOLA EN INTERNET COMO PALABRAS ALADAS. RETO PARA EL TRADUCTOR EXTRANJERO
}

\author{
Katarzyna MADYJEWSKA \\ Universidad de Varsovia \\ k.madyjewska@uw.edu.pl
}

\section{RESUMEN}

Este trabajo trata de las alusiones literarias en la traducción de textos españoles, sobre todo de los artículos de opinión accesibles en Internet. Con la creciente divulgación de la lengua española, y en consecuencia de los estereotipos de la cultura hispana, es más patente que el contacto entre lenguas no coincide con el de las literaturas locales. Además, las nuevas formas de comunicación en Internet, donde accedemos a ediciones digitales de prensa, foros, etc., plantean nuevos retos a la traducción, porque incorporan tanto los registros y contenidos de la cultura de masas como los de la alta cultura. Ésta se manifiesta en frecuentes alusiones a la literatura española, que independizadas de su contexto original se han convertido en las denominadas palabras aladas. Por tanto, un traductor debe elegir entre varias técnicas de traducción para reflejar en la lengua meta un impacto, un juego de palabras, una pretendida mezcla de registros o un idiolecto, que en la lengua original se producen a través del uso de alusiones literarias.

PALABRAS CLAVE: traducción, alusiones literarias, alta cultura, registros, palabras aladas

\section{ABSTRACT}

The article tackles with the subject of literary allusions in translation of Spanish texts available on the internet. Along with the spread of Spanish language, among 
which the Spanish stereotypes have their important impact, we realize that the reciprocity between languages does not convey the subtle liaisons found in the local literary content. Contemporary means and manners of virtual interaction, within which we find newspages, blogs and forums, constitute further challenge in rhetorical model of translation. It is due to the fact that a blended styles and contents of discourse, which mix the mass culture with a high one, can be observed in texts addressed to all different audiences. In case of the participation of the high culture we may encounter certain allusions which became independent from its origin: so called winged words. Hence, a translator shall adopt a technique of translation which would convey in the target language the literary modes such as pun, witty remarks, styles of utterances or idiolect, which are, in the original texts, attained by the mentioned literary allusions.

KEY WORDS: translation, literary allusions, high culture, registers, winged words

Debido al creciente interés por el idioma español en el mundo, la cultura española se difunde cada vez más; y aparte de los estereotipos: corrida, paella, flamenco, etc., que se instalaron como referente universal en el subconsciente de los hablantes de otros idiomas, sus valores literarios se divulgan por doquier. Lógicamente, en el propio territorio español las alusiones a la alta cultura son recursos habituales en los escritores, también entre los periodistas. Mientras los textos que escribían fueron accesibles únicamente a los españoles, no hubo necesidad de preguntarse cuál era la acogida de esas referencias literarias, o si planteaba dificultades entre los no nativos que habían aprendido la lengua española. Sin embargo, ahora la prensa está presente en Internet, y a su lado numerosos blogs, foros y páginas particulares. Acceden a ellos todos los que tienen interés en leer en español, para ampliar sus conocimientos sobre un asunto determinado, para practicar la comprensión de esta lengua o por otros variados motivos. A las fuentes del ciberespacio acuden también periodistas y comentaristas extranjeros, para buscar explicación de algo que pueda intrigar a los lectores de sus países. En ocasiones, estas muestras de expresión escrita exigen traducción por varios motivos. A veces es un traductor profesional a quien una revista encarga traducir un artículo de prensa en español, o bien puede ser el propio periodista quien confiando en su dominio de este idioma se lanza a la tarea de enriquecer su texto con referencias o citas de fuentes extranjeras.

Aquí puede tropezar con expresiones derivadas de la alta cultura, y en concreto de la literatura española, que son explícitas para los habitantes del espacio cultural de origen, aunque no figuren en los diccionarios de modismos o frases hechas. Pueden ser citas literarias de diversa índole: títulos de obras, versos de un poema, nombre de un personaje, frases significativas de un texto conocido o una cita de la tradición literaria. Un traductor, o cualquier lector que al mismo tiempo no disponga de conocimientos literarios del ambiente de la cultural original, puede no darse cuenta de que está ante algo más que una expresión ingeniosa, o bien hurgará en los recursos de su biblioteca o de Internet y descubrirá su origen pero sin intuir el trasfondo. 
Antaño el conocimiento de la alta cultura fue imprescindible para traductores de obras literarias, mientras que para un intérprete o traductor de textos periodísticos especializados, o simplemente más populares, se requería principalmente ser un buen conocedor de la terminología especializada, con un dominio perfecto del uso corriente del idioma. En la actualidad, dada la fácil accesibilidad de fuentes, y pese a la extendida opinión sobre la necesaria especialización de los traductores, estos tropiezan en su carrera profesional con textos muy diversificados, para los que se requiere una cultura literaria avanzada.

Al mismo tiempo, un traductor tiene que mentalizarse y ser consciente de que muchas citas de literatura española, que la mayoría de los españoles suelen conocer por sus lecturas escolares, u otras citas y referencias de obras elevadas a símbolos de ciertos fenómenos sociales, se han desprendido de su contexto original, con frecuencia de manera paradójica o en aparente oposición a ese contexto, y se han convertido en las llamadas «palabras aladas» o «palabras que vuelan». Este nombre trae a la memoria en la tradición antigua, desde Homero, un hablar acertado; y hoy día encabeza listas de citas ingeniosas de rápida divulgación, a menudo poéticas. En el s. XIX, el alemán Georg Büchmann recogió una recopilación de citas famosas de la literatura alemana bajo el título Geflügelte Worte. Siguiendo esta pauta, las palabras aladas en la actualidad suelen definirse como citas de aparición frecuente, en el lenguaje escrito y hablado, utilizadas sin relación a su origen. Pueden proceder de obras literarias, discursos, películas, anuncios publicitarios, etc. Se han independizado de su fuente y viven una vida propia. Destacan por su carácter repetitivo, funcionamiento en contextos incluso dispares y facilidad para contribuir a juegos de palabras e intertextuales ${ }^{1}$. Por su capacidad de condensar numerosas asociaciones culturales, históricas o sociales, las palabras aladas son una herramienta ideal en los textos contemporáneos, que tienden a economizar recursos y expresar mucho con pocos términos. Es notorio que sirven no tanto para nombrar algún fenómeno como para traer a la mente asociaciones al respecto ${ }^{2}$. Pasan a ser recursos de aplicación múltiple cuyo significado se desplaza en función del propósito del autor. Estas expresiones, que remontan a contextos cultos, confirman su estatus de palabras aladas por haber pasado a formar parte de un lenguaje coloquial, y aparecen incluso en discursos de registro vulgar, en hablantes de cuyo nivel cultural cabe dudar. Han pasado de la alta cultura a la baja.

Asimismo, merece la pena resaltar que, por un lado los investigadores observan el fenómeno de una creciente intertextualidad en los textos en Internet, y por el otro opinan que las alusiones a la alta cultura escasean y ceden lugar a la intertextualidad basada en los textos de la cultura de masas ${ }^{3}$. No obstante, un traductor de textos divulgados a gran escala, y en consecuencia receptor de su intertextualidad, no debe conformarse con el conocimiento de códigos culturales básicos, porque en el caso de las alusiones literarias con el papel de palabras aladas debe estar preparado para procesar la información, en paralelo

\footnotetext{
${ }^{1}$ Cf. Chlebda, Wojciech (2002): «Siatka hasłowa przekładowego słownika skrzydlatych słów», Przekład. Język. Kultura, Lublin, UMCS, p. 91. Poprawa, Marcin (2010): «Intertekstualność dyskursu publicznego znak wspólnot komunikacyjnych czy konfliktów», Intertekstualność we wspótczesnej komunikacji językowej, Lublin, UMCS, p. 110.

${ }^{2}$ Poprawa, Marcin , op. cit., p. 111.

${ }^{3}$ Ożóg, Kazimierz (2010): «Kilka uwag o intertekstualności w dobie ponowoczesnej», Intertekstualność we wspótczesnej komunikacji językowej, Lublin, UMCS, p. 66.
} 
entre las dimensiones culta y coloquial del lenguaje. Las palabras aladas dentro de un registro coloquial suponen sin duda un reto para cualquier traductor. En este caso sería ideal que el traductor conociese bien el origen y todas las connotaciones históricas y literarias que una alusión conlleva, para saber decidir si la palabra alada funciona dentro de su cauce original o quizás más bien en este contexto determinado haya derivado a otras funciones; así sabrá diagnosticar qué papel desempeña en el registro de habla del texto.

$\mathrm{Al}$ analizar la aparición de alusiones literarias en textos periodísticos, vemos que escasean en las columnas de noticias corrientes, pero son más frecuentes en las de artículos de opinión. Esto se puede entender por el afán de las primeras para llegar a un foro amplio de lectores, de un nivel cultural imprevisible; mientras que en artículos de opinión los periodistas escriben en un estilo más libre, subjetivo y dejan rienda suelta a asociaciones imaginativas o exageradas. Incluso parece de buen ver que un articulista deje su marca personal de cultura y de juegos intertextuales. Lógicamente los periodistas desean atraer al lector y su oficio exige expresividad. En este aspecto son imitados por autores de blogs y participantes de foros de Internet, que también tienden a impresionar con su brillantez de ideas. Las palabras aladas son un recurso ideal para todos ellos. Su carga contextual y emotiva permite impactar y proporcionar un cariz subjetivo al discurso, acorde con la finalidad que persiguen esos autores. Con mayor o menor consciencia en el uso de estos recursos, intentan destacar entre miles de textos y atrapar la atención del lector.

Es notorio que las palabras aladas de literatura española aparecen en textos que comentan fenómenos muy variados, desde un chismorreo de prensa amarilla hasta noticias de bolsa, lo cual muestra que un traductor de cualquier campo debe contar con una formación filológica. Entre numerosos ejemplos, hemos elegido unos pocos de un empleo llamativo de palabras aladas en contextos diversos. Recordamos su procedencia antes de cada cita.

La obra de teatro de Eduardo Marquina En Flandes se ha puesto el sol:

«España y yo somos así, señora»

Una nota adicional al artículo de ayer sobre modelos productivos y mercado laboral: la inevitable excusa de la cultura empresarial y los empresarios pueblerinos...

http://www.lorem-ipsum.es, 19.01.2010

El poema de Federico García Lorca Verde que te quiero verde:

Vaticano verde que te quiero verde

Según declaraciones del Cardenal Lajolo, el Vaticano tiene la intención de construir una gran planta de energía solar en terrenos, donados por el Estado italiano, cerca del pueblo de Santa Maria de Galeria.

http://infocatolica.com/blog/espadadedoblefilo.php, 24.04.2009

Don Juan Tenorio de José Zorrilla:

Ustedes no se pueden imaginar cómo dejan de bien lavada y planchada una camisa de frac, un pijama de seda, esas prendas que la tata nunca acaba de dejarnos como es debido y que en la tintorería del barrio la dejan a veces imposible para vos y para mí. Ni las manos de monjas de los pocos conventos que aún siguen trabajando estos primores logran tal maravilla.

http://www.tintorerias.com/blog, 27.05.2010 
Cántico espiritual de San Juan de la Cruz:

La soledad sonora de Rodríguez Zapatero y el cambio en Euskadi

El presidente del Gobierno se empieza a quedar solo. Y no sólo en el Congreso de los Diputados porque también en el PSOE se remueven las antiguas poltronas...

http://www.elconfidencialdigital.com, 28.03.2009

El poema Nanas de la cebolla de Miguel Hernández:

Yo estuve ayer en la manifestación. (...) Por cierto, después entré a ver la exposición de Miguel Hernández y me pareció muy interesante, como su maravillosa poesía. Me gustaría que no tuviéramos que volver a escribir las nanas de la cebolla porque tenemos una panda de lerdos ignorantes que se atreven a decir cualquier barrabasada sin sentir ni piedad ni empatía con los que sufren, con las víctimas.

http://www.publico.es/espana, 16.06.2010

\section{La rebelión de las masas de José Ortega y Gasset:}

... la China post-olímpica previsiblemente se abrirá más a las empresas típicas de los países posmodernos, en los que cuentan las energías renovables y la preocupación por el medio ambiente, el ocio y el mayor cuidado por la salud y el deporte, temas todos contenidos en la Villa Olímpica pequinesa El país vive una verdadera «rebelión de las masas» y especialmente en estos sectores España previsiblemente potenciará la cooperación que ya está impulsando.

http://www.realinstitutoelcano.org/analisis, 19.07.2007

Del sentimiento trágico de la vida de Miguel de Unamuno:

Mira, ni idea, ni maldita idea, de las conspiranoias de Raúl y Salgado para ti obvias, para mí desconocidas, ignotas, nada de nada. Como no estoy dentro no lo sé. La verdad, en estas cosas, la única fuente que me sirve es Quique que disfruta de un insider trading que los demás, al menos yo, no tengo. Yo no tengo ni idea de qué desgracias le debes tú a Raúl; yo, ninguna. He comido lo mismo, he tomado copas igual, a mí no me ha robado nada de nada. Debe ser que tengo un menor sentimiento trágico de la vida.

http://elfutbolin.crearforo.com, 26.08.2009

La comedia El perro del hortelano de Lope de Vega:

No se termina de hacer a la idea de que él aparentemente ha rehecho su vida, pero el ex novio también es el perro del hortelano, ni come ni deja comer, pues lo mejor de todo es que, supongo que para demostrarle a mi amiga que estaría dispuesto a reintentarlo, cada vez que hablan aprovecha para quejarse de las múltiples razones por las que no acaba de encontrarse a gusto con la actual.

http://www.mediavida.com/foro, 18.06.2006

El poema de Antonio Machado Caminante no hay camino:

Y es que lo esencial no se oculta antes y después del camino. Lo esencial del camino jacobeo y de todo camino de peregrinación está a la vista en el camino mismo. Los caminos unen porque se hace camino al andar.

La Razón, 25.10.2011 
Vuelva usted mañana de Mariano José de Larra:

Un ordenador para acabar con el «vuelva usted mañana»

La modernización de la administración del Estado ahorrará 150 millones de euros en 2006 y a los ciudadanos 23 millones de horas libres que antes empleaban en burocracia...

http://www.diariodeleon.es, 21.03.2006

La saga/fuga de J.B. de Gonzalo Torrente Ballester:

La saga-fuga de la negociación que no fue pero fue pero no fue sigue impertérrita, a punto de conseguir que nadie se la tome en serio. Con la última entrega queda claro que es el Gobierno español el que rompe las negociaciones al no ir más allá en la consideración de unas propuestas que ETA había puesto sobre la mesa.

http://cotarelo.blogspot.com, 24.07.2007

Los ejemplos anteriores se centraron en el uso directo de una alusión literaria. Sin embargo, un autor puede jugar con ella, como observamos en las siguientes citas.

El título del poemario de Pedro Salinas La voz a ti debida:

La voz de usted, señor Pérez-Reverte, es, en cierto modo, «la voz a nosotros debida»: una explosión de libertad; una liberación desde las glándulas suprarrenales; una catarsis emocional.

http://www.perezreverte.com, 30.08.2010

El burlador de Sevilla y convidado de piedra de Tirso de Molina:

Pero, hay padres que, sin ninguna razón evidente, rehúyen la presencia de los abuelos en la casa de los nietos. Les estorban. O permiten su presencia, como simples convidados (ide piedra o floreros?), pero les niegan cualquier posibilidad de que comenten algo o den su opinión delante de los pequeños.

Mujer Hoy, 27.06.2011

Don Gil de las calzas verdes del mismo autor:

Porque, además los requetelistos de la Agencia Tributaria a los únicos que aprietan las clavijas son precisamente a esos colectivos mientras los ricos, los verdaderamente ricos (y en España hay unos cuantos que todos conocemos) se pasan al fisco por el arco del triunfo. ¿Verdad o mentira? Verdad de la buena. Pues hete aquí, señores, que don Zapatero de las calzas rojas y cortas, ha decidido ya hacer mutis por el foro y que el que venga atrás que arree.

http://www.extraconfidencial.com, 29.10.2010

La novela Cinco horas con Mario de Miguel Delibes:

Cinco horas con Merkel

La canciller despachó pronto su tarea: fue firme con Zapatero en la reunión, le elogió en público y se llevó jamón como regalo.

$A B C, 04.02 .2011$

La letrilla Poderoso caballero es Don Dinero de Francisco de Quevedo: 
Lo peor es que en cuanto quede firme la futura ley, todos se sentarán a la mesa servida, tal como ocurre inocentemente en el Congreso, donde casi cada uno tiene el o los ahijados nombrados en alguna dependencia pública. ¡Poderoso caballero es don zoquete!

$A B C, 23.05 .2004$

Otras alusiones juegan con la tradición literaria. En el caso siguiente con los conceptos del mester de clerecía y mester de juglaría:

Ahora el mester de progresía, reviste un estilismo peatonal y ecológico; el buen progre moderno se desplaza andando o en bicicleta...

$A B C, 26.02 .2010$

O con las palabras atribuidas a Fray Luis de León:

Griñán y Arenas repiten el mismo debate sobre la crisis del último pleno de junio (...) Sin llegar a encabezar su alocución con el «como decíamos ayer» de Unamuno -que a su vez lo tomó de Fray Luis de León-, José Antonio Griñán contestó igual que si no hubieran pasado más de dos meses desde el debate final de junio.

El País de Sevilla, 17.09.2010

Es un verdadero reto cuando a base de palabras aladas se construye un texto entero, tal como en el siguiente artículo de A. Burgos en que, tal vez para alivio de un traductor, se explica la procedencia de su concepto:

Y como si estuviéramos en los «ubi sunt» de las coplas de Jorge Manrique, me pregunto en la noche hermosa del plenilunio: $i$ de las manifestaciones antibelicistas de los subvencionados artistas del Sindicato del Pesebre que se fizo? ¿Do están ahora, mi amor, los que protestaban contra la guerra de Irak en la ceremonia de entrega de los premios Goya (sin premio)?

$A B C, 20.03 .2011$

Otros ejemplos basados en la conocida letrilla de Luis de Góngora:

Ande yo caliente y muérase la gente.

He aquí como la inventiva es, a veces, el peor enemigo de nuestra recalentada madre Tierra. Supongamos que no tenemos agua caliente. Solución: tirar de central térmica, que para eso la energía ni se crea ni se destruye; o sea, que está pero como si no estuviera. ....

Blog de tecnología de El País, 15.03.2007

El moro bueno tiene gas y petróleo así que, o te haces amiguito suyo o te corta el grifo del suministro y llenas el depósito de tu coche con aire o te calientas en el duro invierno con bosta de vaca. El moro bueno tiene algún que otro problemilla con los derechos humanos. Tiene derechos, claro, siempre a favor de los que mandan, sus numerosas familias, los amigos de la numerosa familia y algún que otro dirigente de países hermanos. El resto de la gente corriente no. Pero eso es un problema menor. Ande yo caliente con tu gas y que se joda el represaliado.

El País, 21.03.2011 
La obra de teatro de Antonio Buero Vallejo Historia de una escalera:

Historia de una escalera

Un país es como una comunidad de vecinos. El rey de la escalera no es el administrador, sino los propietarios, de modo y manera que si el ascensor casca, quien se la carga es el administrador. Si además mete la mano en la caja, se le lleva a los tribunales.

La Gaceta en http://www.intereconomia.com, 11.06.2011

Canción del pirata de José de Espronceda:

Para empezar ni los casos de financiación ilegal del PP valenciano, del Fundescam, la trama Gürtel, los perjurios de Camps, el espionaje madrileño, el transfuguismo, etc. etc., parecen hacer mella en el Partido Pirata, mientras que el Gobierno va desgastándose en cada telediario (...). Como decía Espronceda: Que es mi barco mi tesoro, que es mi dios la libertad (pero que) al mismo que me condena yo colgaré de alguna antena. Por desgracia nadie se engaña con estos cantos de sirena. Que el barco de la canción no es el del contribuyente, ni la libertad que predican la que practican, lo sabe hasta el más cateto, quedan lejos el caciquismo y el sufragio censitario.

http://nrikepere.wordpress.com, 27.09.2009

Las funciones ejercidas por las alusiones literarias son variadas. En ocasiones sirven para un título gracioso y llamativo, y entonces basta un modismo ocurrente en la traducción. Igual cuando contribuyen a inyectar una dosis de ironía en un texto. Una palabra alada es capaz de funcionar perfectamente en un contexto completamente trivial y así la de «imposible para vos y para mí» está incorporada en una anécdota sobre tintorerías. Pueden, sin embargo, introducir un estereotipo que ilustra un fenómeno social, como «vuelva usted mañana», «España y yo somos así, señora» o ser símbolo de toda una historia como «las nanas de la cebolla».

En algunos casos los autores mencionan explícitamente la fuente de la cita o por lo menos la introducen entre comillas para aludir a su estatus de frases ajenas, pero a menudo cuentan con la perspicacia del lector. No obstante, tal vez sobrevaloren la de un traductor extranjero, que aunque cuente con una formación filológica adecuada, quizás no disfrute del mismo «baño cultural» que un lector nativo, que le permita reconocer instintivamente y en el acto una alusión, y simplemente es probable que haga caso omiso de ella. Expresiones insólitas o de habla antigua provocan la sospecha del traductor y pueden estimular a recurrir a una fuente de consulta. Pero el título «cinco horas con Merkel» no incorpora elemento inquietante alguno y puede pasar inadvertido. Este es el peor de los casos, cuando un traductor no atisbe la posibilidad de que una frase sea algo más que una construcción sintáctica corriente o una muestra de ingenio del autor de un texto, porque entonces ni siquiera se enfrentará a la resistencia de las palabras aladas en su traducción.

Una misma expresión a veces apunta a significados diferentes en función de las circunstancias. Es imprescindible entonces descifrar y comprender la resonancia que produce en un receptor nativo. Un traductor experimentado sabe perfectamente que la misma expresión, empleada en contextos y por usuarios diferentes, puede atender a diferentes propósitos, y será fundamental la pregunta sobre la finalidad de las expresiones citadas. Dependiendo de la respuesta acudirá a una técnica que le permita comunicar 
de la manera más eficaz posible el mensaje del texto en la lengua meta. Puede recurrir a la ampliación, nota explicativa, paráfrasis, compensaciones, diferentes tipos de equivalencias, omisión, etc ${ }^{4}$. El problema de la barrera lingüística en este caso cede lugar a la barrera cultural, porque si bien existen equivalentes preestablecidos en el caso de obras universales, como la Biblia, pocas obras de la literatura española han ganado terreno en el extranjero. En el país de la autora del presente artículo son conocidos el Quijote o el Cid, y los lectores cultivados tal vez recuerden la traducción maestra del Príncipe Constante y de la Vida es sueño de Calderón de la Barca. Hay otras obras que han engendrado palabras aladas, que pese a estar traducidas resultan familiares a un grupo muy reducido de estudiosos o aficionados a las letras españolas.

Aunque ya por ejemplo Vladimir Nabokov introdujo alusiones a la literatura rusa en su traducción de Alicia en el país de las maravillas, un traductor contemporáneo que pretenda domesticar a la fuerza una palabra alada y sustituirla por otra procedente de su literatura, más familiar al receptor meta, corre el riesgo de engañarlo y además, claro está, no logrará la misma gama de matices y asociaciones en su pensamiento. Más aún, el proceso de comunicación puede resultar fallido. La cultura de la lengua meta ha formado sus propias palabras aladas que no pueden convertirse en equivalentes de las españolas.

Un traductor siempre está en su derecho a introducir una ampliación tipo «como reza una cita de la literatura española...» o similares. Son más complicados los empleos que juegan con una cita para transformarla según el contexto, tal como «poderoso caballero es don zoquete», «la voz a nosotros debida». Si la ironía o un guiño sirven para un juego de palabras, un traductor puede aventurarse a inventar un juego de palabras igual de sorprendente en su propia lengua; aunque sufra una pérdida irreparable del trasfondo porque la comicidad puede surgir no tanto de esa expresión determinada sino del recuerdo del texto de su origen.

En textos periodísticos, blogs, foros, etc., lo esencial sería traducir el impacto que produce una alusión literaria determinada. Porque los ejemplos citados muestran que en la mayoría de los casos desempeña el papel de un recurso para golpear emocionalmente, una especie de arma para penetrar en la imaginación del lector. Así pues, un traductor buscará un modismo o una expresión ocurrente para lograr dicho impacto. Un verdadero rompecabezas son esos textos que se edifican sobre una alusión literaria, como «Ande yo caliente y muérase la gente» o el texto de A. Burgos a base de las Coplas de Jorge Manrique. ¿Cómo conservar el impacto y además acompañado de rima o una nota poética, dentro de un texto que en realidad comenta la economía o la política del país? Un traductor decide dónde está el punto de gravedad del mensaje transmitido y en qué proporción el acento recae en la alusión literaria o en otros aspectos. La presencia de palabras aladas quizás permita expresar rebeldía, distanciamiento, una visión peculiar de la realidad o ser en sí ya una interpretación de la realidad circundante.

Un reto supone también la aparición de alusiones literarias intercaladas en textos de carácter coloquial e incluso vulgar, donde el hecho de que tales expresiones representen un contexto culto introduce un contraste entre registros, unas veces deseado y otras involuntario. De todas formas, un contexto coloquial enriquecido con una palabra alada so-

\footnotetext{
${ }^{4}$ Las técnicas de traducción han sido ampliamente comentadas en numerosas publicaciones y por eso no vamos a desarrollar sus características en el presente artículo.
} 
fisticada gana en originalidad. El papel del traductor consiste en reflejar el contraste mediante los recursos que estén a su alcance en la lengua meta.

Cabe destacar el problema de que en ocasiones el uso de palabras aladas forma parte del idiolecto de un autor, que ha hecho de ellas un guiño dirigido a los lectores y por las que expresa su personalidad, formación profesional y cultural. Un traductor debe estar atento y preparado para agrandar en este caso el repertorio de sus técnicas, porque la traducción tal vez exigirá ampliaciones y explicaciones, para salvar el carácter idioléctico de una expresión particular.

Los traductores suelen enterarse pronto de que las alusiones literarias son difíciles de amansar y no admiten equivalentes directos. El lector actual está saturado de referencias a la cultura de masas y a la vez se acostumbra a que ésta se enriquezca con aportaciones de culturas locales. En los contenidos que un país extranjero aporta a Internet, obviamente coexisten lo que uno conoce con lo que ignora ${ }^{5}$. En tales circunstancias cobra importancia en la traducción el extendido concepto de «importar al autor» en vez de «exportar al lector», que se produce cuando el traductor decide invadir el mundo conocido del receptor con el mundo imaginario de un emisor perteneciente a otro espacio cultural ${ }^{6}$. Por eso, resalta Newark que la «traducción se usa hoy día tanto para transmitir el saber y lograr el entendimiento entre grupos y naciones como para transmitir cultura» ${ }^{7}$. Por tanto, no estaría de más dejar en ocasiones una alusión literaria intacta o solo ligeramente transformada, y con naturalidad incorporar su explicación dentro de la traducción, para de esta manera ampliar el horizonte de imaginación lingüística del receptor.

En conclusión, las alusiones literarias están presentes en contextos sorprendentes y lejanos a la literatura. Al mismo tiempo han dejado de estar tan explícitamente vinculadas a la alta cultura como antaño, porque el estatus de palabras aladas les permite actuar como un recurso de una cultura más baja. La mezcla de registros coloquiales y cultos en forma de alusiones literarias requiere un cuidadoso discernimiento, saber cuál es el propósito al incorporar una cita literaria: contribuir a un impacto mayor en el lector, un juego de palabras, una síntesis de la interpretación de una realidad o el idiolecto de un autor determinado. Por tanto un traductor, además de disponer de conocimientos filológicos profundos, debe saber identificar el propósito del autor y recurrir a una técnica adecuada para poder expresarlo y transmitirlo.

\footnotetext{
${ }^{5}$ Cf. Mocarz, Maria (2010): «Przestrzenie interkulturowo ści w tekstach przewodników turystycznych», Przekład. Język. Kultura, Lublin, UMCS, p. 134.

${ }^{6}$ Cf. Tabakowska Elżbieta (2002): «Bariery kulturowe s zbudowane z gramatyki», Przekład. Język. Kultura, Lublin, UMCS, p. 26.

${ }^{7}$ Newark, Peter (1992): Manual de traducción, Madrid, Cátedra, p. 26.
} 